Linguagem em (Dis)curso - LemD, v. 9, n. 1, p. 61-79, jan./abr. 2009

\title{
"BASEADA EM EVIDÊNCIAS": UMA ANÁLISE DO DISCURSO DE PREVENÇÃO ÀS DOENÇAS*
}

\author{
Luciane Thomé Schröder** \\ João Carlos Cattelan***
}

\begin{abstract}
Resumo: Este artigo analisa o discurso de prevenção às doenças, tendo como foco uma empresa de planos de saúde, a Unimed. O material tomado como base da análise são quatro textos: dois fôlderes, uma mensagem informativa que acompanha o talão de pagamentos e um texto publicado no boletim informativo da empresa. Os conceitos utilizados no estudo provêm da Análise de Discurso e da Retórica (esta última posta sob o viés discursivo).

Palavras-chave: discurso; ethos; topos; plano de saúde.
\end{abstract}

\section{INTRODUÇÃO}

Para a organização deste estudo, estaremos apresentando uma análise que se divide em três momentos: na primeira parte, tomaremos como objeto dois panfletos "informativos" e um texto de menor destaque sobre câncer de colo de útero que acompanha os boletos bancários. Estes textos são exemplos dos materiais que chegam ao cliente da

\footnotetext{
* Este texto é parte integrante de atividade de pesquisa realizada com os informativos da Unimed no decorrer de doze meses. Os textos escolhidos para análise são tomados como representativos da totalidade do seu conjunto, considerando-se, portanto, que a leitura desses objetos tenham por fundamento as mesmas conclusões, ou seja, que, por entre as linhas do discurso do cuidado com a saúde do cliente, encontra-se um não-dito que denuncia, por parte da empresa, uma preocupação de ordem financeira.

** Professora do Curso de Letras da Universidade Estadual do Oeste do Paraná (UNIOESTE), campus de Marechal Cândido Rondon. Doutoranda em Estudos da Linguagem (área de concentração Estudos do texto/discurso) na Universidade Estadual de Londrina (UEL). E-mail: <ltschroder@brturbo.com.br>.

*** Professor da Universidade Estadual do Oeste do Paraná (UNIOESTE), campus de Marechal Cândido Rondon, e do Mestrado em Letras da mesma universidade, campus de Cascavel. Doutor em Linguística e Língua Portuguesa. E-mail: <cattelan@brturbo.com.br>.
} 
Unimed, mensalmente, e cujo conteúdo varia, a cada mês, sempre versando sobre assuntos relacionados à saúde. $O$ que se procurará verificar, neste momento, é a predominância de um mesmo topos argumentativo que reitera uma forma de comportamento que o usuário deveria adotar como cliente Unimed, o qual, no caso, diz respeito à prática de prevenção de doenças. $\mathrm{Na}$ segunda parte, serão analisados recortes do texto "informativo" pertencente à manchete "Medicina Baseada em Evidências", a fim de verificarmos como se organizam os argumentos e, também, a apresentação de discursos politicamente corretos que passam a estabelecer a relação da empresa com os clientes. Podemos verificar, nesta oportunidade, que os sujeitos são representantes de valores que sustentam uma sociedade e que engendram os discursos, como, por exemplo, máximas já estereotipadas como " $a$ saúde em primeiro lugar", sendo atribuída a esta um valor incomensurável. $\mathrm{Na}$ última parte, concentrar-nos-emos nos efeitos de sentido dos enunciados utilizados a fim de apresentar, por meio de recortes, como, com seus dizeres, a Unimed busca construir um ethos persuasivo, com vistas a levar os clientes a se tornarem usuários mais conscientes e menos onerosos para a empresa (obviamente, esse "desejo" da empresa não é explicitado, por razões que, pode-se dizer, feririam a face positiva da empresa).

Para este estudo, estamos mobilizando conceitos oriundos da Análise de Discurso, da Semântica Argumentativa e da Retórica (as duas últimas disciplinas sendo olhadas a partir de uma perspectiva discursiva) ${ }^{1}$. Os conceitos que vão fundamentar a análise comungam de uma perspectiva dialógica de linguagem, entendendo-se que esta é afetada, sempre, pelas condições de produção dos discursos - já que é na prática da enunciação que os discursos efetivamente se constituem em discursos - que a impregnam de valores socioculturais e ideológicos provindos da sociedade em que o discurso é produzido. Entendemos que os autores se valem dos valores que são articulados, mais ou menos conscientemente; ao enunciarem (no caso, os autores dos informativos)

\footnotetext{
${ }^{1}$ Grosso modo, estamos entendendo que o que diferencia a Semântica Argumentativa e a Retórica, de um lado, e a Análise do Discurso, de outro, refere-se ao modo como cada uma delas concebe a criação dos processos discursivos: enquanto as duas primeiras tomam o sujeito como bastante consciente das opções que faz (um estrategista), a segunda o consideraria como sendo escolhido pelas opções de constituição da teia discursiva, por causa do seu papel e do seu lugar social e da formação discursiva a que pertence.
}

SCHRÖDER; CATTELAN - "Baseada em evidências"... 
desejam, de alguma forma, afetar os enunciatários, para que estes possam ser convencidos a aderir aos convites que a empresa faz: previna-se, procurenos, podemos ajudá-los. Estes enunciados sugerem um efeito de amabilidade, de preocupação e de cuidado que é incorporado pelo cliente a partir de uma memória que aciona um discurso de ethos maternal, por exemplo, como aquele usado por pessoas que zelam pelas outras e se preocupam com elas, não dispensando falas de sobreaviso ao outro, de cuidados para consigo próprio. O discurso da Unimed é o discurso maternal vigilante, que está atento, e mais: além de "alertar", ainda se coloca à disposição para auxiliar em caso de necessidade (previna-se, procure-nos, podemos ajudá-los).

Sabe-se que algumas coisas podem ser ditas e outras não. As que podem ancoram-se em discursos fundadores que fornecem enunciados que se querem éticos, corretos e verdadeiros: enfim, discursos que as pessoas desejam ouvir. Por outro lado, ao mesmo tempo, silenciam (em troca do dito) o que poderia ser tomado como discurso desautorizado, porque seriam discursos agressivos, amorais e antiéticos (de acordo com determinada sociedade). Dizer previna-se para não nos fazer gastar à toa, procure-nos quando efetivamente precisar para não consumir consultas à toa e podemos ajudá-los, caso seja efetivamente necessário, são exemplos daquilo que, de acordo com o discurso selecionado, talvez a empresa desejasse dizer, mas ela sabe que não pode fazê-lo, sob pena de perder seus clientes.

Isso explica o discurso produzido pela empresa e que apela ao pathos dos clientes. A relação, neste caso, é marcada por questões econômicas e de saúde, ou, quem sabe, da ordem do politicamente correto: de saúde e economia. Em todo caso, a luz vermelha avisa que explicitar esta relação pode resultar em efeitos não desejados. Antecipando-nos à análise, podemos dizer que há nos textos escolhidos duas formações discursivas que, parece-nos, não devem ser tratadas concomitantemente, porque, sabe-se (isso é lição de casa!), a saúde é uma prioridade; basta retomar um discurso comumente ouvido e divulgado: "sou pobre, mas tenho saúde: isto é o que importa!". E as vistas grossas que se fazem dizem respeito ao fato de que todos, inclusive os que buscam uma fuga no discurso do conforto mencionado, sabem que, em primeiro lugar, está a condição financeira do sujeito que tem condições de pagar pelo acesso aos meios que lhe propiciam saúde: mas isto é algo que não pode ser dito, porque 


\section{4}

afronta uma condição que não deveria ser negada a ninguém, mas o é; têm garantia de acesso à saúde aqueles que podem pagar por ela. Em todo caso, essa existência afeta a ordem dos discursos, sobretudo, daqueles que necessitam vender o que, em tese, deveria ser gratuito. Pode-se, pois, fazer a hipótese de que exista o interesse da Unimed na economia por parte dos clientes e de que tal defesa esteja pautada em questões socioideológicas da sociedade.

É, portanto, por essa trilha de reflexão que tomaremos o discurso que compõe o informativo da Unimed e seus dois panfletos, objetivando revelá-los nas suas estratégias, desejadas ou não por aquele que enuncia, entendendo que elas não são nem totalmente ingênuas, nem totalmente maquiavélicas; é discurso que obedece a certos "interesses", que julgamos subjetivamente como bons ou não, de acordo com o modo como eles nos afetam.

\section{O DISCURSO DA PREVENÇÃO: AS FORMAS TÓPICAS}

Para o desenvolvimento desta seção, tomaremos como base os estudos de Ducrot (1989) a partir do texto Argumentação e “topoi” argumentativos, para indicar como, no discurso em estudo, marcam-se formas tópicas que podem ser descritas como "quanto mais se previne, menos doença se tem" e "quanto menos se previne, mais doença se tem". Para o autor, o topos é um lugar comum argumentativo, entendido como aquilo que sustenta o que falam os participantes de uma comunidade de crença e que permite relações estruturantes articulando-se sobre relações manifestadas na língua, e que revelam conceitos positivos e negativos, os quais se desenvolvem por meio de escalas e gradações.

Para o autor, o topos é portador de três propriedades:

Primeiro, ele é "universal" [...] uma comunidade linguística admite partilhá-lo [...] A segunda propriedade dos topoi é a generalidade: o princípio deve ser reputado válido, além da situação na qual é aplicado, para um grande número de situações análogas. [...] Esta generalidade decorre imediatamente do que chamei "universalidade". [...] O ponto mais importante [...] é uma terceira 
característica [...] os topoi [...] são de natureza "gradual". (DUCROT, 1989, p. 24-26)

Tomaremos este postulado teórico como fio condutor para as análises efetuadas, ou seja, tomaremos determinados enunciados e buscaremos observar como a argumentação da Unimed se estrutura levando em consideração, prioritariamente, esta conclusão do autor: "Ainda que a utilização da língua exija que se disponha de topoi, a língua não determina o conteúdo específico destes topoi. [...] O que é necessário é a existência de topoi reconhecidos pela coletividade" (DUCROT, 1989, p. 38). Ou seja, os enunciados que compõem o que, à primeira vista, parecem ser os textos "informativos" da Unimed têm, em sua estrutura, formas argumentativas que induzem um modo de leitura direcionada para a defesa de um ponto de vista: o da prevenção. Entretanto, o que é dito só se configura em prática argumentativa, porque, de alguma forma, o que está expresso e sendo direcionado pelos mecanismos linguísticos vale-se de topoi aceitos pelos membros da sociedade em que circulam. É desta forma que a persuasão se constitui, porque esses valores são partilhados: no caso do discurso da saúde, eles são os mesmos valores.

\subsection{As análises}

Cancer de Colo de Utero: prewina!

Você que é cliente Unimed sabe que nossa proposta é mai sampla do que a simples assistência médica e que, fundamentalmente, queremos ajudá-la a permanecer saldável. Se você tem entre 25 e 29 anos, lembre-se de realizar o Exame Preventivo de Cancer de Colo de Utero a cada 12 meses.

Como preveriir é muito melhor - e mais saudáxwel - do que remediar, sugerimos que vocês visite seu médico regularmente. Ele poderá esclarecer suas dúwidas e encaminhar o seu pedido de exame.

"Existem doenças que as pessoas já nẵo precisam ter, basta preverir".

Se você precisa de mais informações, estatemos sempre prontos para atendê-la.

\section{Equipe de Medicina Preventiva da Unimed Cascavel}

O procedimento de análise será o de recortar enunciados para, assim, demonstrar como eles constituem formas tópicas:

Enunciado 1: Câncer de Colo de Útero: previna! O topos que sustenta o enunciado pode ser descrito como deve-se prevenir contra 
o câncer de colo de útero. Neste caso, as formas tópicas são quanto mais se previne, existe menos probabilidade de desenvolver câncer de colo de útero e quanto menos se previne, mais chance de desenvolver o câncer de colo de útero se tem. Destacamos, aí, a forma injuntiva da flexão verbal previna, acompanhada da exclamação, que pode ser entendida como uma ordem: previna, porque, quanto menos se previne, mais possibilidade de desenvolver a doença se tem. A prevenção, portanto, é o princípio discursivo da Unimed, porque, de acordo com seu lugar argumentativo, ele acompanha a crença universal de que "melhor prevenir do que remediar", que se sustenta em argumentos baseados em evidências médico-científicas divulgadas, como, por exemplo, por meio dos conhecidos exames de mamografia e próstata, que podem impedir o desenvolvimento de câncer. Há, ainda, os chamados exames de rotina, também preventivos, que objetivam detectar doenças antes que elas manifestem os sintomas (o que já indicaria um quadro avançado da doença). $\mathrm{O}$ que se evita, agindo-se dessa forma, isto é, prevenindo-se, é a doença, o que ocasiona menos despesa e menos doença; consequentemente, menos gasto com cliente e menos despesa para a empresa (quem sabe, mais lucro por decorrência).

Enunciado 2: Você que é cliente Unimed sabe que nossa proposta é mais ampla do que a simples assistência médica e que, fundamentalmente, queremos ajudá-la a permanecer saudável. Neste enunciado, o topos argumentativo está calcado no argumento de que ser cliente Unimed é ter mais que assistência médica, é permanecer saudável. As formas tópicas correspondentes são: a) quanto mais cliente Unimed, mais do que assistência médica você terá e, portanto, mais saudável permanecerá e b) quanto menos cliente Unimed você for, menos assistência médica terá e, portanto, menos saudável será. Chamamos a atenção para a presença do índice de domínio fundamentalmente, cujo efeito de sentido permite inferir que ajudar o cliente a permanecer saudável é o objetivo maior da empresa, o que valida a sua argumentação. Tem-se, ainda, a presença da informação pressuposta pelo verbo permanecer, que permite que se diga que o cliente Unimed já é saudável e, por isso, o trabalho da empresa é o de fazer com que ele permaneça neste estado; por isso, ele deve se prevenir. O vocativo você cria o efeito de que o 
cliente Unimed tem exclusividade, possuindo, portanto, um valor que aqueles que não são clientes da Unimed não desfrutam. Ao dizerem queremos ajudá-la, tem-se a expressão de um desejo (queremos) e uma opção de aceite ou recusa dada ao cliente, ou seja, a Unimed está oferecendo ajuda, cabendo ao usuário aceitála (e a culpa consequente, se, por teimosia, não acatar o conselho dado). Por fim, o adjetivo simples permite que se faça a inferência de que apenas os outros planos de saúde oferecem simples assistência médica, o que não ocorre com a Unimed, cuja preocupação é preventiva.

Enunciado 3: Se você tem entre 25 e 29 anos, lembre-se de realizar o Exame Preventivo de Câncer de Colo de Útero a cada 12 meses. As formas tópicas, a partir do topos argumentativo $O$ exame de câncer de colo de útero, entre 25 e 29 anos, deve ser feito a cada 12 meses, são quanto menos se fižer o exame de prevenção a cada 12 meses, há mais probabilidade de desenvolver a doença, e quanto mais se fizer o exame de prevenção a cada 12 meses, há menos probabilidade de desenvolver a doença. O lugar comum argumentativo, novamente, é o da prática da prevenção, no caso do câncer de colo de útero, entre as idades de 25 e 29 anos. A partícula condicional se articula uma relação de condicionalidade obrigatória entre uma certa idade e a realização do exame de prevenção numa época restrita a 12 meses, o que permite inferir, por um lado, que a realização após 12 meses pode se constituir em dois problemas: primeiro, se a mulher esperar mais que 12 meses, a doença pode se encontrar em estágio avançado, prejudicando sua saúde; e, segundo: se ela esperar mais que 12 meses e tiver desenvolvido o câncer, a empresa terá que honrar seus compromissos, pagando as despesas médicas da paciente, o que significa que o enunciado, mais do que uma lembrança, é, também, uma forma de a Unimed evitar, por meio da prevenção, gastos desnecessários. Por outro lado, pode-se inferir, ainda, que também num intervalo menor do que 12 meses o exame não deve ser feito, pois isto geraria gastos desnecessários com exames seguidos em intervalos de tempo que não são recomendados, inclusive pelos médicos. 
Enunciado 4: Como prevenir é muito melhor - e mais saudável - do que remediar, sugerimos que você visite seu médico regularmente. $\mathrm{O}$ topos argumentativo geral em que se baseia o enunciado é prevenir é mais importante que remediar. As formas tópicas que balizam a constituição do enunciado são quanto mais se previne, mais saúde se tem e menos se precisa remediar e quanto menos se previne, menos saúde se tem e mais se deve remediar. $\mathrm{Na}$ segunda parte do enunciado, o topos argumentativo é deve-se visitar o médico regularmente, o que leva à elaboração das seguintes formas tópicas: quanto menos visitar o médico regulamente, menos se previne e quanto mais visitar o médico regularmente, mais se previne. O lugar argumentativo alerta para a necessidade de ir ao médico. No caso da Unimed, esse expediente justifica a necessidade de ter um plano de saúde, ou seja, o cliente paga uma mensalidade, mas ele também está sendo avisado, por meio de uma sugestão, de que deve visitar o médico regularmente (gasto, portanto, bem empregado). O efeito de sentido do termo visitar pode ser entendido como uma prática de manutenção da saúde, ou seja, de prevenção. O cliente não está doente e, ao visitar o médico (o que é quase um passeio), pode evitar a propagação de alguma doença. A leitura que fazemos novamente é que, evitando a doença, menos gasto a Unimed tem. $\mathrm{O}$ advérbio de intensidade que diz que prevenir é muito melhor atua argumentativamente, objetivando a persuadir o paciente a ir ao médico regularmente, levando a empresa a evitar gastos e a ter menos despesa ou mais lucro.

Enunciado 5: "Existem doenças que as pessoas já não precisam ter, basta prevenir". O topos argumentativo geral é as pessoas não precisam ter certas doenças e devem se prevenir. As formas tópicas, novamente, são quanto mais prevenção, menos doença e quanto menos prevenção, mais doenças. O discurso da prevenção é reiterado, praticamente, em todos os enunciados, que alertam o cliente sobre doenças que ele não precisa ter; o marcador de pressuposição já age argumentativamente no texto, assim como a flexão verbal basta, no sentido de levar ao entendimento de que prevenir é uma ação simples que evita doenças. As aspas 
reforçam a argumentação de um discurso que circula sobre uma mesma base de argumento: o da prevenção.

Por fim, o enunciado 6: Se você precisa de mais informações, estaremos sempre prontos para atendê-la. $O$ topos argumentativo se estrutura a partir de uma postura de disponibilidade da empresa para com o cliente, ou seja, estamos prontos a atendê-la em suas dúvidas. Em razão do efeito de sentido que emerge do marcador de pressuposição sempre, as formas tópicas são quanto mais necessidade de informação, mais a Unimed está disponivel e quanto menos informação, menos a Unimed está disponivel, pois, neste caso, ela não é necessária; ou seja, a postura da empresa é a de estar ao lado do cliente, evitando a todo custo o desenvolvimento de doenças desnecessárias por meio da prevenção.

Somando-se a esse discurso, em que foram revelados alguns topoi argumentativos, outros dois enunciados serão apresentados, porque se valem do mesmo ponto de vista. Eles se encontram em dois pequenos fôlderes que, como outros, acompanham os informativos. No primeiro deles, tem-se a apresentação de um dos projetos da Unimed, voltado para a terceira idade, intitulado Bem Viver $^{2}$, em que, na extremidade superior, aparece a foto de um casal idoso. Abaixo da foto, pode-se ler: "Amigo beneficiário: se você tem mais de 60 anos participe deste programa. Sua saúde agradece". O segundo fôlder traz, como no primeiro, na sua extremidade superior, uma imagem, que é a foto de um cigarro, cuja fumaça desenha as feições de um rosto cadavérico, meio fantasmagórico, que acompanha o seguinte dizer: "Apague o cigarro da sua vida!". Este fôlder faz parte da divulgação do projeto Antitabagismo 3 . Abaixo da foto do cigarro, tem-se o enunciado: "Se você fuma e não consegue parar, procure-nos. Podemos ajudá-lo”.

\footnotetext{
${ }^{2} \mathrm{O}$ projeto Bem Viver faz parte de um programa para a terceira idade cujo objetivo é incentivar a prática de atividades físicas como alongamento, caminhada, exercícios localizados, atividades mentais e manuais. As informações aqui citadas encontram-se no verso do fôlder que é assinado pelo Departamento de Medicina Preventiva.

${ }^{3} \mathrm{O}$ projeto Antitabagismo objetiva dar apoio às pessoas que desejam parar de fumar, por meio de reuniões semanais em que os pacientes seriam acompanhados por médicos pneumologistas e psicólogos. As informações aqui citadas encontram-se no verso do fôlder. Como no primeiro fôlder, este também vem assinado pelo Departamento de Medicina Preventiva.
} 
Em relação ao primeiro enunciado, "Amigo beneficiário: se você tem mais de 60 anos participe deste programa. Sua saúde agradece", apresenta-se o topos argumentativo você deve participar do programa Bem viver, pois mais saúde terá. As formas tópicas, portanto, seriam quanto menos participar do programa, menos saúde você terá e quanto mais participar do programa, mais saúde você terá. Considerando que o programa é assinado pelo Departamento de Medicina Preventiva, tem-se, no objetivo de contribuir com a saúde do cliente, um programa preventivo, em que o cliente é levado a praticar exercícios físicos que podem cooperar para a manutenção da boa saúde, justamente numa idade em que a falta de atividades físicas implica uma série de complicações próprias da idade. Desta forma, pode-se dizer que há no enunciado, de forma implícita, um topos argumentativo que afirma que quanto mais se previne, mais saúde se tem.

Em relação ao enunciado pertencente ao segundo fôlder citado, tem-se "Se você fuma e não consegue parar, procure-nos. Podemos ajudá-lo". O topos argumentativo que o sustenta é se alguém fuma e não consegue parar, precisa procurar ajuda. As formas tópicas seriam quanto mais dificuldade alguém tem para parar de fumar, mais ajuda precisa procurar e quanto menos dificuldade alguém tem para parar de fumar, menos ajuda precisa procurar, o que seria o desejável, já que a voz que sustenta o enunciado elaborado pertence ao Departamento de Medicina Preventiva e se deve levar em conta os efeitos de sentido da injunção de procure-nos, nós podemos ajudá-lo com grupos de apoio e a presença de especialistas. A Unimed se mostra, assim, como desejando que, antes que doenças causadas pelo cigarro se manifestem, o cliente a procure a fim de parar de fumar e, com isso, evite a predisposição ao surgimento delas. Novamente e, neste caso, de forma explícita, tem-se o topos argumentativo do discurso da prevenção: previna-se, pare de fumar, procure-nos, nós podemos ajudá-lo, ou seja: o fundamento de crença é que, quanto mais a pessoa se previne, mais saúde tem.

Como se pode perceber, o topos argumentativo que constitui o discurso da prevenção do câncer de colo de útero, da prevenção às doenças da terceira idade e da prevenção às doenças causadas pelo cigarro é, em todos os casos, as pessoas devem se prevenir contra as doenças. As fórmulas variantes presentes nas formas tópicas se estruturam sobre os mesmos princípios enunciativos, que vão ao encontro do topos argumentativo escolhido pela empresa, ou seja, o da manutenção da 
saúde do cliente, mas também, pode-se dizer, da tranquilidade da vida econômica da cooperativa, já que, quanto menos doença os clientes desenvolverem e mais eles se prevenirem contra elas, menos gastos eles darão e mais lucros a Unimed terá.

\section{ARGUMENTAÇÃO E CLASSES ARGUMENTATIVAS}

A análise do discurso do texto "Medicina Baseada em Evidências: saiba mais sobre esse procedimento", materialidade central do informativo em estudo, está estruturado em quatro partes, sendo a primeira uma apresentação geral do assunto cujo foco central se volta para uma explicação. Os três parágrafos seguintes são estruturados a partir de classes argumentativas, conforme procuraremos demonstrar. Este princípio teórico é definido como: "Uma classe argumentativa é constituída de um conjunto de enunciados que podem igualmente servir de argumento para uma mesma conclusão" (KOCH, 1997, p. 30). Buscamos detectar aqui, portanto, as classes de argumentos que constituem o discurso da Unimed e que buscam conduzir o leitor ao ponto de vista desejado pela empresa de venda de planos de saúde.

Para a análise, faremos a reprodução das quatro partes do texto, enfocando sua organização argumentativa.

Parágrafo 1: A Medicina Baseada em Evidências (MBE) é uma prática que tem se popularizado nos meios médicos mundiais $\mathbf{e}$ pode ser encarada como uma evolução natural. Ela consiste na aplicação, pelo médico, de resultados de pesquisas científicas na hora de escolher o melhor tratamento para cada tipo de problema clínico. Por isso, procure discutir com seu médico sobre a utilização desse procedimento, já que a medicina baseada em evidências tem se mostrado a melhor opção para o paciente.

Destaca-se deste trecho, primeiramente, o operador e que soma argumentos a favor de uma mesma conclusão. Podemos observar que ele estabelece uma relação de continuidade entre a parte um do enunciado e a parte dois, de forma que a segunda parte vem se somar à primeira, de modo que algo popularizado passa a ter como "sinonímia" evolução natural. Essa primeira explicação aos usuários da Unimed, parece-nos, deseja, de 
forma simplificadora, porém articulada por uma nuance de cientificidade, alicerçar, com Medicina Baseada em Evidências, o cerne argumentativo do que a Unimed pretende defender a seguir. Estes dois enunciados são o pano de fundo que sustenta os demais. Na sequência, explica-se o que é MBE. Isso se verifica no enunciado seguinte, onde se lê Ela consiste na aplicaşão, pelo médico, de resultado de pesquisas científicas na hora de escolher o melhor tratamento para cada tipo de problema clínico. São três os dados que justificam a valorização da cientificidade defendida: a) a explicitação e a explicação de que a sua aplicação é feita pelo médico, não deixando margem à inferência de que, consciente dos sintomas de uma doença e sobre suas possíveis evidências, encaminhamentos possam ser dados por qualquer outro profissional que não seja médico. Isso se deve, talvez, à importância que este profissional possui frente a, por exemplo, os enfermeiros e as pessoas em geral; b) os resultados partem de evidências autorizadas pela ciência, ou seja, são o resultado de pesquisas científicas, de onde se pode inferir um distanciamento de outros conhecimentos que não aqueles determinados por resultados de incansáveis processos de pesquisa. O termo 'pesquisa' remonta às instituições acadêmicocientíficas que, em nossa sociedade, são tidas como fontes tradicionalmente conhecedoras e reveladoras de saberes; c) o discurso da individualidade - que faz com que o sujeito se sinta exclusivamente tratado, sendo a exclusividade um valor disseminado na sociedade, que, comumente, nega as diferenças socioeconômicas, por exemplo - é explicitado pela passagem o melhor tratamento para cada tipo de problema clínico. Ressaltamos, contudo, que os problemas não são citados, o que descompromete quanto à quantificação do alcance da Medicina Baseada em Evidências, o que provocaria a pergunta: a que tipos de problemas, exatamente, a MBE remete? A MBE aparece, assim, como uma solução geral e global da medicina, cujo reconhecimento só os médicos possuem. Por fim, não se pode deixar de citar a semelhança que a sigla MBE estabelece com outra sigla, bastante difundida nos meios acadêmicos voltados aos negócios, a MBA, o que, de alguma forma, atribui ao nome, enquanto sigla, um gosto pelo estrangeirismo, de acordo com aqueles que acham que o conhecimento estrangeiro é superior aos conhecimentos produzidos no país.

$\mathrm{Na}$ sequência, o operador argumentativo por isso introduz uma conclusão para os argumentos citados: Por isso, procure discutir com seu 
médico sobre a utilização desse procedimento. Se o MBE é popular nos meios médicos mundiais, se é uma evolução natural e se é resultado de pesquisas científicas para cada tipo de problema, então, por meio do uso de por isso, o discurso procura não deixar dúvidas de que ele deva ser adotado pelo paciente. Mas a Unimed não determina; ela diz ao usuário para discutir com o seu médico. De novo, manifesta-se o discurso individualista (não é com qualquer médico, mas o seu) que busca provocar, no usuário, o desejo de procurar pelo médico para discutir a sua condição de saúde. Percebemos na passagem o uso de uma estratégia: se o procedimento é novo, não é o médico que levará o paciente a conhecêlo, mas o paciente é que requererá do médico informações previamente disseminadas pela Unimed (via informativos), demonstrando seu interesse em conhecer a MBE e obrigando, assim, o médico e a Unimed a tratamentos inovadores, que, em teoria, podem trazer benefícios. Porém, o que parece ficar mais evidente é justamente a contribuição da Medicina Baseada em Evidências para uma relação econômica. Ou seja, as evidências apontam a causa, o que pode implicar a não necessidade, por exemplo, de uma série de exames.

$\mathrm{O}$ arremate final fica por conta do já que que antecede a parte final do enunciado: já que a medicina baseada em evidências tem se mostrado a melhor opção para o paciente, em que a Unimed silencia qualquer menção a interesses próprios e afirma que se trata de uma melhor opção para o paciente. Este primeiro parágrafo argumenta, portanto, para a explicação de por que a opção pela MBE é a melhor.

Parágrafo 2: O fator que torna a MBE ainda mais confiável e eficiente é a utilização de provas científicas rigorosamente apuradas, que norteiam as decisões sobre o tratamento e ainda melhoram a literatura médica. $O$ trabalho do médico, dessa forma, é otimizado, já que ele pode aliar novas evidências científicas à experiência e ao conhecimento que já possui.

Neste segundo parágrafo, a constituição de uma classe argumentativa é evidenciada por meio dos operadores ainda mais, e e ainda. Inicia-se o enunciado retomando o parágrafo anterior, em que uma série de argumentos foi tecida a fim de mostrar a MBE como a melhor opção para o diagnóstico clínico. Na sequência, o texto promete apresentar mais um fator, mas que apenas reitera um argumento já apresentado, ou seja, de que a confiabilidade e eficiência da Medicina 
Baseada em Evidências está no uso de provas científicas rigorosamente apuradas. Novamente, temos o uso da voz autorizada da ciência que prova e apura dados rigorosamente. $\mathrm{Na}$ do enunciado, por meio do operador $e$ ainda, tem-se melhoram a literatura médica. Nada menos questionável, portanto; afinal, o que é exposto na literatura são os registros que permitem a pesquisa, a aprendizagem e o acesso ao conhecimento: os livros desfrutam desse status; no caso, a literatura é médica, o que lhe agrega ainda mais valor. Conforme já foi exposto, o argumento da Unimed se dá por meio do uso da voz de verdade que é anunciada pela instituição da ciência.

Para finalizar o parágrafo, a presença do operador já que introduz a justificativa e a conclusão do raciocínio: $O$ trabalbo do médico, dessa forma, é otimizado, já que ele pode aliar novas evidências científicas à experiência e ao conbecimento que já possui. Sendo a MBE confiável, eficiente, usuária de provas científicas rigorosamente apuradas e inovadoras da literatura médica, ela só pode, é claro, otimizar o trabalho do profissional que já detém saberes (aliar conhecimentos àqueles que o médico já possui) e que, por meio da MBE, acresce ao seu repertório novos saberes, que são evidências: e sobre evidências científicas não pairam dúvidas. A subjetividade que poderia transparecer nos argumentos, já que se está falando do mensurável pelo olhar humano, é "amenizada" por meio da crença universal que inter-relaciona duas práticas de poder: uma que advém da medicina e seu status social e outra das ciências. Juntas e atuando para o bem da paciente, ao leigo pouco cabe argumentar.

Parágrafo 3: Em síntese, pode-se dizer que a Medicina Baseada em Evidências alia conhecimento e experiência clínicas aos problemas de cada paciente. Implica, além disso, em calcular e comunicar os riscos e os benefícios das diferentes ações ao paciente.

Por fim, o terceiro parágrafo fecha a discussão: a MBE propicia a exatidão que se espera e deseja do procedimento médico. Ela traz conhecimento (é um procedimento confiável e eficiente, que se vale de pesquisas rigorosamente apuradas), alia experiência (adquirida ao longo do tempo pelos procedimentos científicos, o que lhes confere legitimidade, porque são comprovados por métodos e técnicas), é voltada para os problemas de cada paciente (que é único e exclusivo), calcula (pela rigorosidade) e comunica riscos e benefícios das diferentes ações (porque ela não 
vê apenas um diagnóstico, mas oferece opções a partir das experiências e comprovações baseadas em evidências científicas).

Parágrafo 4: Converse com seu médico e peça mais detalhes sobre esse procedimento que a Unimed de Cascavel já desenvolve com sucesso. Você é o maior beneficiário dessa prática.

Ao final, a injunção para que o paciente converse e procure o médico: não é o médico que irá impor a nova técnica (popularizada nos meios médicos mundiais), mas é o paciente que a solicitará. A confiabilidade do método é destacada pelo fato de que a Unimed o desenvolve com sucesso, ou seja, com todas as garantias de sua eficiência. Para não restar dúvidas quanto ao interesse da Unimed, ela o explicita no último enunciado "Você é o maior beneficiário dessa prática": você, cliente Unimed.

Não se diz em nenhum momento o quanto essa prática pode se tornar econômica nos meios médicos, sobretudo para as cooperativas de saúde que são empresas e, como empresas, visam ao lucro. Talvez a Medicina Baseada em Evidências seja um grande avanço para que, sobretudo, as sociedades mais carentes de recursos possam se valer dela para tratar seus doentes. Porém, nas circunstâncias em que o discurso ocorre e no meio em que ele é utilizado, não nos parece que o princípio crucial de argumentação seja a preocupação com a divulgação do novo método clínico de diagnósticos, por uma razão: a circularidade com que se procura assegurar uma vontade de verdade - no caso, de que a MBE é um método que visa beneficiar o cliente exclusivamente - silencia algo que parece bem mais profundo do que se diz: a preocupação com a saúde da própria Unimed.

\section{O ETHOS}

Esta última parte tem como objetivo verificar, em alguns dos enunciados recolhidos do corpus, o ethos que se estabelece pelo e no discurso. Cremos que seja essa presença de um eu que emerge do discurso que justifica a própria existência da prática discursiva como o ato enunciativo, que é não aleatório, nem arbitrário. Trata-se de uma 
prática discursiva que se constrói por meio de crenças e valores que asseguram a ela, e, sobretudo, ao locutor, uma imagem diante dos interlocutores e que lhe assegurará a condição necessária para interagir e agir sobre o outro.

O texto tomado para análise e, até então, nomeado como informativo (porque ele se deseja assim) possui uma outra finalidade: ao dar "informação" sobre novidades na saúde e sobre a existência de projetos para beneficiar o usuário, no caso, a partir do discurso da prevenção, a Unimed constrói uma imagem de si, que se deseja positiva. $\mathrm{O}$ fato de, ao enunciar algo, aquele que o faz fala algo de si mesmo, sem fazê-lo explicitamente, é o que se tem chamado de ethos. Não se diz eu sou bom, sou confiável, sou amigo, mas se mostra isto pelo discurso enunciado. É o discurso, portanto, que permitirá ao outro dizer algo sobre o locutor: ele é bom, ele é amigo, ele é confiável. Por esse motivo, podemos dizer que a Unimed busca criar, por meios aparentemente "informativos", uma campanha publicitária elogiosa de si.

O conceito de ethos é oriundo da retórica clássica e tem sido revisitado por especialistas das mais diversas perspectivas. Este re-olhar para o conceito traz na obra de Amossy (2005) um conjunto de textos que o abordam a partir da perspectiva interacionista, da pragmática, da semântica, da análise do discurso e da retórica, por exemplo, oferecendo aos leitores uma visão importante a ser retomada na análise de discursos. É desses estudos que nos valemos, a fim de verificar como a empresa "fala" de si e, ao fazê-lo, constrói uma autoimagem positiva que serve para fins práticos: manter clientes e conquistar novos clientes.

Recorte 1: Amigo beneficiário: se você tem mais de 60 anos, participe deste programa. Sua saúde agradece.

Chamamos a atenção para a forma usada pela Unimed para se dirigir aos clientes: Amigo beneficiário. O cliente da empresa não é um pagante de mensalidade, ele é mais: ele é um amigo. Podemos dizer que o uso do termo amigo aciona pelo menos dois efeitos de sentido imediatos: proximidade e afetividade. Este último efeito de sentido talvez seja o mais importante: afinal, tem-se por amigos aquelas pessoas a quem desejamos o bem. Amigo não se faz da noite para o dia, mas é uma conquista a partir da troca de sentimentos igualitários entre duas (ou mais) pessoas, como a confiança e a segurança. É com os amigos que 
podemos contar; são eles que estão(rão) sempre ao nosso lado: vive-se sem um amor, mas não se vive sem amigos. $\mathrm{O}$ ideal romântico sobre a amizade sobrepõe-se a todos os conflitos e ainda é tido como um dos valores conquistados pelo homem pelos quais não se paga (basta lembrar a crença de que "amizade não tem preço"). O interdiscurso retoma da memória tais ditados que se associam a momentos em que se é tratado como amigo(a). E a Unimed chama seu cliente de amigo, e mais: de beneficiário, de modo que se pode inferir: "você não é um cliente, você é um beneficiário dos nossos serviços: você é nosso amigo". Tem-se, pois, uma imagem de empresa amiga, preocupada com a saúde dos beneficiários e amigos. Para assegurar o convite à participação no programa, que, no caso, é voltado para os idosos, a Unimed ilustra o fôlder de onde o enunciado foi tirado com a foto de um casal de aproximadamente 60 anos, ambos demonstrando estar em ótima saúde e felizes, pressuposição que se faz devido ao sorriso e ao gesto carinhoso da mulher que beija meigamente a bochecha do companheiro.

Recorte 2: Se você fuma e não consegue parar, procure-nos. Podemos ajudá-lo.

O que nos interessa desse enunciado é a forma como a empresa constrói uma imagem de solícita, ou seja, ela se coloca à disposição do cliente. Ao dizer procure-nos que podemos ajudá-lo, ela deixa implícito que tem condições de fazê-lo. Ela tem certeza na realização e no êxito da tarefa. No caso, a tarefa não é das mais fáceis: ela deseja combater um vício. Assim, ela se afasta da banalidade e se mostra presente mesmo diante das tarefas mais árduas. A empresa soma, pois, à imagem de amiga a de empresa amiga, à disposição e competente.

Por fim, recorremos ao texto do informativo já tratado no segundo momento deste estudo. Nele, a Unimed se mostra a par das novidades da medicina (apresentando, no caso, o que seria o diagnóstico da Medicina Baseada em Evidências), mas, sobretudo, ratifica que a sua maior preocupação é o beneficiário. E, como não poderia deixar de ser, está à concorrência (inclusive entre os pares). Assim, um dado a mais deve ser destacado: não é qualquer Unimed que já trabalha com os benefícios da MBE, mas a Unimed de Cascavel. Desta forma, a empresa dessa cidade constrói individualmente uma imagem de si que a colocaria 
à frente das outras filiais, suas concorrentes, como pode ser observado no recorte abaixo:

Recorte 3: Converse com seu médico e peça mais detalhes sobre esse procedimento que a Unimed de Cascavel já desenvolve com sucesso. Você é o maior beneficiário dessa prática.

\section{BREVES CONSIDERAÇÕES FINAIS}

Objetivamos mostrar, com essa análise, como a Unimed, empresa de venda de planos de saúde, organiza, no material discursivo usado para análise, uma argumentação que se pauta em topoi argumentativos que revelam crenças e valores que são socialmente partilhados: por isso, são tomados como argumentos respaldados por uma voz coletiva que já os incorporou. Além disso, buscou-se verificar como, por meio desse discurso, ela cria um ethos que a mostra como amiga, solícita, confiável, inovadora e preocupada com o cliente: sem dizê-lo. É por meio destes, dentre outros jogos, que se fazem os discursos, práticas nem sempre sabidas pelos que enunciam, mas apreensíveis por meio de hipóteses que buscam compreender os princípios que regulam os discursos, isto é, a "vontade" de levar um discurso ao outro e, dentre outras tantas finalidades, convencer, persuadir, impor e coagir: ser aceito, enfim. E lucrar, neste caso específico: ou, pelo menos, não colocar a empresa em risco.

\section{REFERENCIAS}

AMOSSY, R. Imagens de si no discurso: a construção do ethos. São Paulo: Contexto, 2005.

DUCROT, O. Argumentação e "topoi” argumentativos. In: GUIMARÃES, Eduardo (Org.). História e sentido na linguagem. São Paulo: Pontes, 1989. KOCH, I. V. A inter-ação pela linguagem. 3. ed. São Paulo: Contexto, 1997. 
Recebido em 16/07/08. Aprovado em 17/12/08.

Title: "Based on evidence": a discourse analysis of illnesses prevention

Author: Luciane Thomé Schröder; João Carlos Cattelan

Abstract: This study analyses the discourse of illnesses prevention, focusing on Unimed, a health insurance company. The corpus consists of four texts: two folders, an informative message that accompanies the invoices and a text published in the company's newsletter. The concepts adopted in the analysis derive from Discourse Analysis and from Rhetoric (the latter considered under a discursive view).

Keywords: discourse; ethos; topos; health insurance.

Titre: "Basée dans des évidences": une analyse du discours de prévention aux maladies

Auteur: Luciane Thomé Schröder; João Carlos Cattelan

Résumé: Cette étude analyse le discours de prévention aux maladies, ayant comme focalisation une entreprise d'assurance maladie, l'Unimed. Le matériel employé dans l'analyse concerne quatre textes: deux folders, un message informatif qui vient avec le ticket de payements et un texte publié dans le bulletin informatif de l'entreprise. Les notions employées dans l'analyse viennent de l'Analyse du Discours et de la Rhétorique (celle-ci placée sous le biais discursif).

Mots-clés: discours ; ethos ; topos ; plan d'assurance maladie.

Título: "Basada en evidencias": un análisis del discurso de prevención a las enfermedades

Autor: Luciane Thomé Schröder; João Carlos Cattelan

Resumen: Este estudio analiza el discurso de prevención a las enfermedades, teniendo como foco una empresa de planes de salud, Unimed. El material tomado como base del análisis son cuatro textos: dos folletos, un mensaje informativo que acompaña el talonario de pagos y un texto publicado en el boletín informativo de la empresa. Los conceptos utilizados en el análisis provienen del Análisis de Discurso y de la Retórica (esta última puesta bajo la óptica discursiva).

Palabras-clave: discurso; ethos; topos; plan de salud. 